\title{
Escassez hídrica: estudo de caso em uma comunidade rural do pantanal mato-grossense
}

A água é um recurso de grande importância para o desenvolvimento e sobrevivência humana, porém a problemática referente à sua quantidade e qualidade representa motivo de preocupação mundial. O objetivo deste estudo foi apresentar a situação das famílias que sofrem com a escassez hídrica, por meio do relato das mulheres que residem no Assentamento Laranjeira I, situado na borda do Pantanal de Cáceres - MT. À coleta de dados adotou-se abordagem qualitativa descritiva, de caráter exploratório e como método de pesquisa optou-se pelo estudo de caso com a utilização de questionário estruturado, entrevista semiestruturada proposta por Kaufmann rodas de conversa e registros em diário de campo. A amostra reuniu 20 famílias. No que diz respeito ao abastecimento de água $70 \%$ das famílias tem como fonte de água principal as minas (nascentes) que são obtidas por meio de gravidade, bombas, baldes e famílias. No que diz respeito ao abastecimento de água $70 \%$ das famílias tem como fonte de água principal as minas (nascentes) que são obtidas por meio de gravidade, bombas, baldes e
outros recipientes. Todas as famílias entrevistadas alegaram recorrer às fontes alternativas como as nascentes para a coleta de água para o consumo humano e armazenar a água em galões e garrafas pet. Através das falas foi possível constatar que pouco se avançou no processo de obtenção de água, no entanto algumas famílias conseguiram adquirir água em seus lotes através da perfuração de poços. As familiais utilizam moto, carro, bicicleta como meio de locomoção para a coleta de água. No Assentamento Laranjeiras I também foi constatado que muitas famílias por vezes ansiaram pelo desejo de ir embora do assentamento devido a problemática da falta de água. Foram observados também conflitos entre os moradores do assentamento relacionado ao uso da água, onde famílias disputam por minas e lançam mão de estratégias como a instalação de diversos encanamentos que levam a água às residências. Foi possível identificar também que as famílias adotaram medidas de adaptação para superar a falta de água como a coleta e captação da água da chuva. Por fim, esta realidade da comunidade estudada evidencia a necessida de de alta vulnerabilidade na qual essa parcela da população está inserida e considerar as múltiplas dimensões e a diversidade de desafios para a efetividade de ações setoriais, como são as intervenções em abastecimento de água para consumo humano.

Palavras-chave: Escassez Hídrica; Assentamento Rural; Água potável.

\section{Case study: case study in a rural community of pantanal mato grossense}

\begin{abstract}
Water is a resource of great importance for human development and survival, but the problem of quantity and quality is a matter of worldwide concern. The objective of this study was to present the situation of families suffering from water scarcity, through the report of the women residing in the settlement Laranjeira I, located on the edge of the Pantanal of Cáceres - MT. To the data collection a descriptive qualitative approach was adopted, with an exploratory character. As a research method, a case study was carried out using a structured questionnaire, a semi-structured interview proposed by Kaufmann, conversation wheels and field diary records. The sample had 20 families. As far as water supply is concerned, $70 \%$ of households have as their main source of water the mines (springs) that are obtained by gravity, pumps, buckets and other containers. All families interviewed claimed to use alternative sources such as the springs for collecting water for human consumption and storing the water in gallons and pet bottles. Through the lines it was possible to verify that little progress was made in the process of obtaining water, however some families were able to acquire water in their lots through the drilling of wells. The family's use a motorcycle, a car, a bicycle as a means of locomotion for the collen been observed among residents of the wate was also possible to identify that the families adopted adaptation measures to overcome the lack of water, such as the collection and collection of rainwater. Finally, this reality of the studied community evidences the need for structural transformations and actions that aim to increase access to water supply systems. Addressing those excluded from access requires acknowledging the highly vulnerable situation in which this part of the population is inserted and considering the multiple dimensions and diversity of challenges for the effectiveness of sectoral actions, such as interventions in water supply for human consumption.
\end{abstract}

Keywords: Water Scarcity; Rural Settlement; Potable Water.

Topic: Desenvolvimento, Sustentabilidade e Meio Ambiente

Reviewed anonymously in the process of blind peer.

\section{Nayara Ferreira (iD)}

Universidade do Estado de Mato Grosso, Brasil

http://lattes.cnpq.br/6859869981962154

http://orcid.org/0000-0001-7528-2821

nayferreira go@hotmail.com

Amanda dos Santos Bernardes Pinheiro

Universidade do Estado de Mato Grosso, Brasil

http://lattes.cnpq.br/1962523342210459

http://orcid.org/0000-0002-2126-2208

oficina amanda@hotmail.com

Caroline Mari de Oliveira

Universidade do Estado de Mato Grosso, Brasil

http://lattes.cnpq.br/2216258795802689

http://orcid.org/0000-0002-6099-0953

oliveiracaroline29@gmail.com

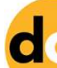

DOI: 10.6008/CBPC2179-6858.2018.001.0007
Received: 02/02/2018

Approved: 20/05/2018

\author{
Solange Kimie Ikeda Castrilon (iD \\ http://lattes.cnpq.br/3373034135331436 \\ Universidade do Estado do Mato Grosso, Brasil \\ http://orcid.org/0000-0003-1862-4615 \\ ikedac@gmail.com
}

Josué Ribeiro da Silva Nunes (iD

Universidade do Estado de Mato Grosso, Brasi

http://lattes.cnpq.br/3292016056510295

http://orcid.org/0000-0003-3927-5063

josue@unemat.br

\section{Referencing this:}

FERREIRA, N.; PINHEIRO, A. S. B.; OLIVEIRA, C. M.; CASTRILON, S. K. I; NUNES, J. R. S.. Escassez hídrica: estudo de caso em uma comunidade rural do pantanal mato-grossense. Revista Ibero-Americana de Ciências Ambientais, v.9, n.1, p.88-102, 2018. DOI: http://doi.org/10.6008/CBPC2179-6858.2018.001.0007 


\section{INTRODUÇÃO}

A água é um recurso de grande importância para o desenvolvimento e sobrevivência humana, porém a problemática referente à sua quantidade e qualidade representa motivo de preocupação mundial. Apesar da grande quantidade de água presente no planeta, a escassez hídrica é uma realidade em muitas regiões do mundo, sendo que apenas uma pequena parcela é adequada para o consumo humano e não se encontra distribuída equitativamente (GREY et al., 2013).

Quase 750 milhões de pessoas, sobretudo as mais pobres e vulneráveis são privadas desse direito humano fundamental. Cerca de 2,3 bilhões de pessoas obtiveram o acesso a fontes de água potável desde 1990. Embora os progressos no que tange ao acesso à água potável tenham ocorrido, existem ainda disparidades significativas. Dos 748 milhões de pessoas em todo o mundo que ainda não têm acesso à água potável, $90 \%$ vivem em áreas rurais e estão sendo deixados à margem dos progressos alcançados por seus países (WHO, UNICEF, 2008).

De acordo com o relatório Joint Monitoring Programme for Water Suplly, Sanitation and Hygiene publicado pelo Fundo das Nações Unidas para a Infância - UNICEF (2016), ainda existem muitas disparidades com relação ao acesso à água e ao esgotamento sanitário. Enquanto as populações que vivem em regiões mais desenvolvidas conseguiram acesso universal a estes recursos, 48 países considerados de baixo desenvolvimento apresentam grandes deficiências. Isto demonstra que, apesar dos avanços, as populações mais vulneráveis são as que seguem em desvantagem com relação ao acesso à água potável e ao esgotamento sanitário (WHO; UNICEF, 2016).

O relatório do Programa Conjunto de Monitorização (JMP, na sigla em inglês), Progress on drinking water, sanitation and hygiene: 2017 update and Sustainable Development Goal baselines publicados pela Organização Mundial da Saúde (OMS) e UNICEF, o qual apresenta a primeira avaliação global dos serviços de água potável e saneamento com gestão segura. O relatório que avalia os progressos de água potável, saneamento e higiene de acordo com os Objetivos do Desenvolvimento Sustentável (ODS) ${ }^{1}$ conclui que muitas pessoas, até o ano de 2017, não têm acesso a água e saneamento seguros, em especial, em áreas rurais (WHO, UNICEF, 2017).

Entre as principais conclusões do referido relatório estão: muitos países carecem de dados sobre a qualidade dos serviços de água e saneamento; existem grandes lacunas no serviço entre áreas urbanas e rurais. O relatório da OMS e UNICEF (2017), por exemplo, aponta que das 161 milhões de pessoas que utilizam água de fontes não tratadas como lagos, córregos, rios ou canais de irrigação, 150 milhões vivem em áreas rurais, revelando as disparidades no acesso à água potável entre populações de áreas urbanas e rurais.

A falta de água potável para o consumo humano e as disparidades com relação ao acesso foi constatada de maneira singular em uma comunidade rural, denominada de Assentamento Laranjeiras I, o qual está localizado na região do Pantanal mato-grossense. Paradoxalmente, este assentamento que

\footnotetext{
${ }^{1}$ Em Assembleia Geral das Nações Unidas no ano de 2015 foram elaborados os ODS, com o intuito de dar continuidade aos avanços proporcionados pelos (Objetivos do desenvolvimento do Milênio - ODM) criados no ano de 2000, mas agora incluindo princípios dos direitos humanos, reafirmando a importância da declaração Universal dos Direitos Humanos, bem como de outros instrumentos internacionais relativos aos direitos humanos e ao direito internacional.
} 
enfrenta problemas socioambientais relacionados à escassez hídrica está localizado em uma região que apresenta grande volume de água sendo considerada a maior área úmida continental do planeta, (CASTRILLON, et al., 2017).

Embora o Assentamento Laranjeiras I esteja situado em um contexto de abundância hídrica, a população sofre com a escassez de água potável. Portanto, frente a este cenário buscou-se compreender como a comunidade convive com a escassez de água, por meio do relato das mulheres do Assentamento Laranjeiras, bem como compreender quais são suas estratégias de adaptação.

Entender como as comunidades assentadas reagem frente à questão da falta de água e dos impactos do ambiente em que vivem, consiste em pontos fundamentais na busca da qualidade de vida da comunidade, na promoção da saúde, na conservação dos recursos naturais e na sensibilização em relação aos problemas ambientais da região.

É importante que sejam pesquisadas formas de resistência a esses problemas, não apenas no âmbito tecnológico, mas principalmente a partir de uma melhor compreensão das particularidades da cultura local e das percepções dos indivíduos e suas comunidades e que venham da expressão e das identidades das pessoas que estão na linha da vulnerabilidade.

\section{REVISÃO TEÓRICA}

\section{A água em um contexto de escassez e o acesso e qualidade em comunidades rurais}

A água e a gama de serviços providos por esse recurso contribui para a redução da pobreza, para o crescimento econômico e para a sustentabilidade socioambiental. Desde a segurança alimentar e energética até a saúde humana e ambiental, contribuindo para as melhorias no bem-estar social e do crescimento inclusivo (UNESCO, 2015).

De acordo com os dados do relatório da OMS e UNICEF (2017), existe uma realidade alarmante com relação à oferta deste bem tão necessário à sobrevivência, onde cerca de 3 em cada 10 pessoas (2,1 bilhões) não têm acesso à água potável e disponível em casa. E 6 em cada 10 pessoas (cerca de 4,5 bilhões) carece de saneamento seguro.

Em torno de 263 milhões de pessoas se deslocam mais de 30 minutos para ter acesso a uma fonte de água segura, como um dos resultados todos os anos 361 mil crianças com idade inferior a 5 menos morrem devido a diarreia. Transmissão de doenças como cólera, disenteria, hepatite A e febre tifoide estão associadas a inacessibilidade à água potável e ao saneamento seguros ao bem-estar humano. São estes os números que revelam a desigualdade socioambiental e inserem o acesso a água segura, como problemática socioambiental para o cumprimento dos 17 objetivos para o desenvolvimento sustentável até o ano de 2030 (ONU, 2015).

Questões relativas ao acesso regular à água potável e segura tem causado preocupação, principalmente, nos países em desenvolvimento que sofrem com a rápida expansão urbana, do adensamento populacional e da ocupação de áreas urbanas e rurais com evidentes deficiências e dificuldades no suprimento de água para satisfazer as necessidades básicas diárias (RAZZOLINI; GÜNTHER, 2008). Esta 
constatação dos autores supracitados é confirmada no relatório da OMS e UNICEF (2017) que relevam as disparidades no acesso à água adequada para consumo humano entre populações que vivem em áreas urbanas e rurais em países da América Latina, Caribe, África e Ásia.

Analisando o aspecto econômico, podemos afirmar que as melhores condições de abastecimento de água estão disponíveis para quem pode arcar com os gastos provenientes de seu uso. Como por exemplo, os bairros onde a população é de baixa renda (favelas, vilas, áreas de assentamento) acabam convivendo mais com a irregularidade no abastecimento de água, diferentemente dos bairros habitados pelas classes com ganhos elevados que pouco sofre com problemas no fornecimento de água, constituindo, assim, um dos problemas socioambientais (SILVA, 2012).

O relatório do Programa de Monitoramento Conjunto (JMP, na sigla em inglês), Progress on drinking water, sanitation and hygiene: 2017 update and Sustainable Development Goal baselines, apresenta a primeira avaliação global dos serviços de água potável e saneamento com gestão segura. A conclusão é que muitas pessoas ainda não têm esse acesso, sobretudo em áreas rurais (WHO; UNICEF, 2017). Segundo o Relatório de Desenvolvimento Humano (PNUD, 2006), há três características que podem esclarecer a baixa cobertura de abastecimento na área rural:

1) escassez local: o problema seria a insuficiência de fontes de água que perdurem o ano todo, onde muitas têm secas sazonais;

2) comunidade e fornecedores: normalmente a responsabilidade pela manutenção, pela busca e pela expansão da fonte de água parte da iniciativa da própria comunidade, portanto há menor ação por parte dos governos locais;

3) política e pobreza: a população rural, geralmente pobre e dispersa, ainda se encontra marginalizada no que diz respeito às ações políticas.

No Brasil, 72,2\% da população rural ainda acessa água apenas por meio de poços, cacimbas, açudes e barreiros, acesso esse muitas vezes precário e com grande potencial para provocar doenças (FUNASA, 2017). Neste cenário de grandes incertezas interligadas a aceleração das mudanças na oferta de água, se torna indispensável uma melhor compreensão dos valores e processos envolvidos nas relações entre indivíduos e entre estes e seu meio ambiente, ou seja, a relação homem e natureza.

\section{METODOLOGIA}

\section{Tipo de estudo}

Este artigo trata-se de uma pesquisa do tipo qualitativa, descritiva, de caráter exploratório e como método de pesquisa optou-se pelo estudo de caso, sendo que seu objeto de estudo se encontra classificado com relação aos seus objetivos na investigação exploratória e descritiva.

Ainda com relação ao objetivo desta pesquisa, entende-se que também pode ser classificada como pesquisa descritiva, a qual tem como objetivos a descrição de características de determinada população ou fenômeno ou as relações estabelecidas entre estes, "são incluídas neste grupo as pesquisas que têm por objetivo levantar as opiniões, atitudes e crenças de uma população" (GIL, 2002). Segundo este autor, as 
pesquisas exploratórias são aquelas em que se busca uma maior familiaridade com o problema e o aprimoramento de ideias ou a descoberta de intuições.

O estudo de caso, conforme Godoy (1995) caracteriza-se como uma pesquisa cujo objeto é uma unidade que se analisa profundamente com o exame detalhado de um ambiente, de um sujeito ou de uma situação em particular, uma vez que ele permite um amplo e detalhado conhecimento do tema em questão. O estudo de caso constitui uma etapa muito importante, que possibilita o máximo de informações possíveis, através da coleta de dados, viabilizando o entendimento da situação real do problema estudado.

\section{Área de estudo}

Com relação ao local da pesquisa, optou-se pelo Assentamento Laranjeiras $\mathrm{I}^{2}$ localizado no município de Cáceres, Mato Grosso, que integra a mesorregião do centro-sul mato-grossense e a microrregião do Alto Pantanal. Faz fronteira entre Brasil e Bolívia e abrange uma área territorial de $24.796,8 \mathrm{~km}^{2}$ (IBGE, 2000). Este assentamento está em uma região de transição dos biomas Cerrado e Pantanal que the coloca em uma localização geográfica como o primeiro município na formação de área alagável do Pantanal Mato-grossense (SILVA; BINZSTOK, 2013). Segundo Kreitlow et al. (2013) a Baía Grande do Pantanal que é interligada com o Pantanal no município de Poconé, localiza-se a cerca de $7 \mathrm{~km}$ da sede do Assentamento Laranjeiras I.

Este assentamento localiza-se nas coordenadas $57^{\circ} 33^{\prime} 41,83^{\prime \prime}$ Oeste e $16^{\circ} 34^{\prime} 04,10^{\prime \prime}$ Sul, conforme a figura 1. A unidade geomorfológica da área é a Província Serrana. A área está inserida na Bacia do Alto Paraguai (BAP), sendo abastecida por diversas nascentes que convergem, principalmente, da serra do Bocainão, e de dois cursos d'água, que deságuam na Baia Grande no Pantanal mato-grossense (CASTRILLON et al., 2017).

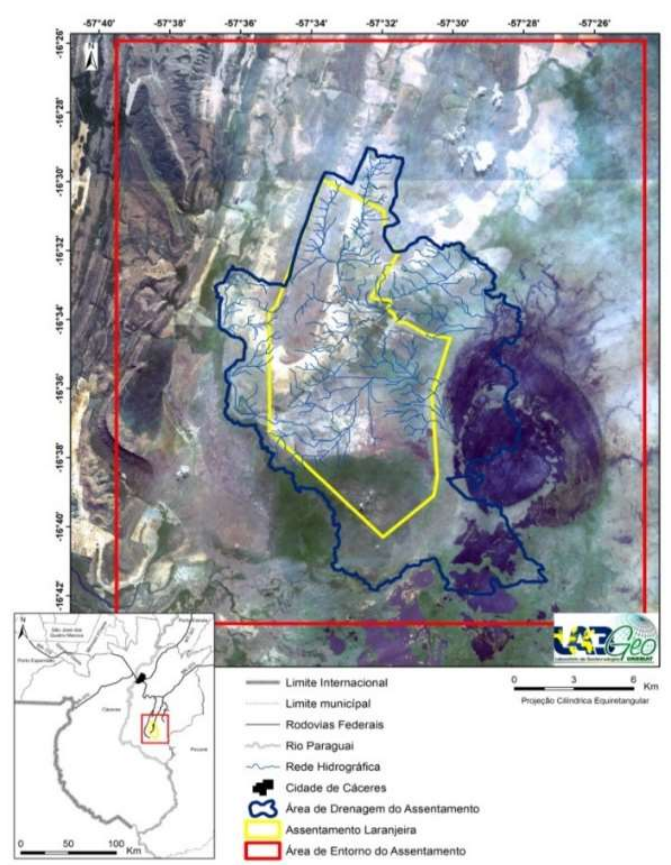

Figura 1: Carta imagem com limites do Assentamento Laranjeira I e área da microbacia com a indicação da rede hidrográfica e diversas nascentes na região do assentamento, no município de Cáceres-MT. Fonte: Castrillon et al.

(2016).

\footnotetext{
${ }^{2}$ Este assentamento foi instituído pelo Instituto de Colonização e Reforma Agrária (INCRA) no dia 24 de fevereiro de 1997. Tem área total de 10.944 hectares e possui 125 famílias assentadas (BRASIL, 2014).
} 
Quanto ao procedimento norteador desta pesquisa, cumpre dizer que a obtenção de dados sobre a situação do abastecimento de água ocorreu por meio da pesquisa qualitativa, aplicada por meio de questionários, entrevistas semiestruturadas e observações dos locais de estudo, seguidas de anotações em um diário de campo com o intuito de compreender melhor a realidade em questão, conforme orienta Bernand (1988).

A pesquisa envolveu 20 moradoras da área de estudo no período de 04 de novembro de 2017 a 21 de fevereiro de 2018, optou-se por escolher o público feminino para a aplicação dos questionários e entrevistas trazendo como justificativa a escolha pelo público feminino porque na ausência de água, são as mulheres e crianças que formam o grupo mais vulnerável.

A coleta de dados foi iniciada somente após a aprovação do projeto pelo Comitê de Ética em Pesquisa (CEP) sob o Parecer no: 2.290.691 em 21 de setembro de 2017, e mediante a assinatura do Termo de Compromisso das Instituições Envolvidas no estudo e do Termo de Consentimento Livre e Esclarecido (TCLE) daqueles que concordaram em participar, conforme determinação da Resolução CNS (Conselho Nacional de Saúde) 466 de 12 de dezembro de 2012 do Ministério da Saúde.

O primeiro passo no processo de investigação foi à realização da entrevista piloto. Posteriormente, escolheu-se a roda de conversa por se tratar de uma técnica metodológica que propicia uma comunicação dinâmica e produtiva entre comunidade e pesquisadores. A escolha dessa técnica - Roda de Conversa ocorreu principalmente por sua característica de permitir que os participantes expressem, concomitantemente, suas impressões, conceitos, opiniões e concepções sobre o tema proposto (MELO; CRUZ, 2014).

As discussões nas Rodas de Conversa foram pautadas na temática: "Escassez hídrica" e na sequência ocorreu à aplicação do questionário com o intuito de verificar a situação das comunidades rurais no que se refere ao abastecimento de água potável.

Como método de condução das entrevistas semiestruturadas, foi utilizado a abordagem da Entrevista Compreensiva desenvolvida pelo sociólogo francês Jean-Claude Kaufmann, o qual orienta que na condução da pesquisa seja possibilitado uma boa sociabilidade entre pesquisador e participante com ambiência favorável em campo, bem como permite uma maior aproximação entre a produção da teoria e a pesquisa empírica, destacando a relação dialógica com o entrevistado.

Após a aplicação da entrevista compreensiva, deu-se início a análise dos dados através do momento de escuta e da transcrição das gravações. Posteriormente, as informações foram agrupadas por categorias de análise conforme cada objetivo proposto e realizadas as discussões pertinentes com base nas teorias relativas ao assunto.

\section{RESULTADOS E DISCUSSÃO}

Através do projeto de restauração ecológica intitulado Recuperação das nascentes e fragmentos de mata ciliar do córrego do Assentamento Laranjeiras I e também da mobilização para a conservação dos recursos hídricos no Pantanal mato-grossense realizado de forma participativa entre uma equipe 
interdisciplinar de pesquisadores da Universidade do Estado do Mato Grosso e comunidade local, foi possível identificar que os moradores sofrem com a falta de água, e esta situação da escassez hídrica nos assentamentos foi o ponto de partida para o processo de investigação acerca de como estas comunidades convivem com esta realidade e suas formas de adaptação.

No tocante, para uma melhor compreensão da realidade em questão, constatou-se, por meio das técnicas da pesquisa qualitativa empregadas no presente estudo, que o conjunto do espaço geográfico deste possuem diversos problemas socioambientais, motivados por pressões ambientais provenientes da agricultura, pecuária extensiva e do desmatamento que têm se constituído nos municípios do entorno do Assentamento Laranjeiras I. Pelo fato deste assentamento situar-se em uma área entre o cerrado e pantanal, também sofre com as pressões que incidem sob esses biomas, em especial, provenientes das ações antrópicas, expansão do agro e hidro negócio que reduzem a variedade das espécies de fauna e flora, degradam os recursos naturais, efetuam ocupações desordenadas e grilagem de terras, provocam incêndios florestais e focos de calor, esvaziamento do campo que propicia grandes perdas na biodiversidade.

Com relação às pressões sofridas no assentamento podemos citar a falta de proteção das nascentes que foi identificado através de um diagnóstico participativo realizado pelos pesquisadores e moradores que indicou que quase todas as nascentes, reservas de água e córregos, no espaço do assentamento, estavam com a sua vegetação original destruída e se encontravam degradados e ameaçados pelo pisoteio das nascentes pelo gado, com isso se propôs o replantio da mata ciliar, de preferência com a vegetação nativa.

Dessa forma, as populações mais vulneráveis, como é o caso do universo pesquisado neste estudo, sofrem e relatam em suas falas os problemas socioambientais supracitados, em especial, quando mencionam que a água está diminuindo e que a situação piora no período da estiagem, quando a coleta de água pelas mulheres do assentamento é intensificada. Frente a este cenário buscou-se compreender como a comunidade convive com a escassez de água, por meio do relato das mulheres do Assentamento Laranjeiras, bem como compreender quais são suas estratégias de adaptação.

\section{Realidade do Assentamento Laranjeiras I: Perfil das entrevistadas}

Através da análise dos dados apresentados na Tabela 1 constatamos que $65 \%$ das mulheres entrevistadas tinham mais de 40 anos, e que $85 \%$ das famílias sobrevivem com renda familiar de 1 a 2 salários mínimos tendo como chefe de família o homem.

Tabela 1. Caracterização do perfil das moradoras do assentamento Laranjeiras I

\begin{tabular}{|c|c|c|}
\hline Variáveis & № & $\%$ \\
\hline \multicolumn{3}{|l|}{ Faixa etária } \\
\hline 30-35 anos & 7 & $35 \%$ \\
\hline 40 anos & 13 & $65 \%$ \\
\hline \multicolumn{3}{|l|}{ Renda Familiar } \\
\hline Abaixo de 1 salário mínimo & 3 & $15 \%$ \\
\hline 1 a 2 salários mínimos & 17 & $85 \%$ \\
\hline \multicolumn{3}{|l|}{ Chefe de família } \\
\hline Homem & 13 & $65 \%$ \\
\hline Mulher & 7 & $35 \%$ \\
\hline \multicolumn{3}{|l|}{ Profissão } \\
\hline Dona de casa & 10 & $50 \%$ \\
\hline
\end{tabular}




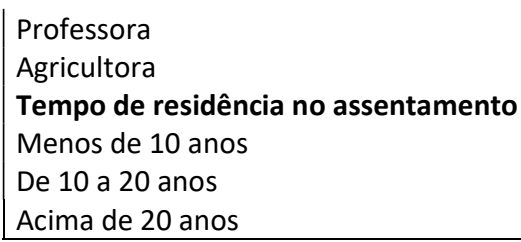

\begin{tabular}{lc|}
6 & $30 \%$ \\
4 & $20 \%$ \\
1 & $5 \%$ \\
8 & $40 \%$ \\
11 & $55 \%$ \\
\hline
\end{tabular}

Como profissão metade das entrevistadas atuam como donas de casa que é uma característica típica de famílias de comunidade rural, 6 entrevistadas atuam na área da educação como professoras e 4 mulheres como agricultoras. Com relação ao tempo de residência no assentamento mais da metade das famílias residem no local há mais de 20 anos, seguido de 8 famílias que residem entre 10 a 20 anos e uma família há menos de 10 anos.

No que diz respeito ao abastecimento de água $70 \%$ das famílias tem como fonte de água principal as minas (nascentes) que são obtidas por meio de gravidade, bombas, baldes e outros recipientes. Metade das famílias dispõe de poços em suas residências, no entanto todas as famílias entrevistadas alegaram recorrer às fontes alternativas como as nascentes para a coleta de água para o consumo humano.

Habitualmente, as famílias rurais necessitam recorrer às formas alternativas de abastecimento, coletivos ou individuais, utilizando frequentemente água bruta para o consumo doméstico. As fontes mais comuns de água são os rios, nascentes e poços que podem ser distribuídas para os domicílios de uma comunidade por ação coletiva, com o uso de um reservatório comum, ou são as próprias famílias que providenciam as suas formas de abastecimento de água, buscando diretamente na fonte utilizando baldes e vasilhas ou por meio de bombas (PNUD, 2006).

As entrevistadas relataram utilizar a água da fonte principal essencialmente para beber, tomar banho, escovar os dentes e cozinhar. Quando questionadas sobre o armazenamento da água para o consumo humano $100 \%$ alegaram armazenar a água em galões e garrafas pet, como demonstrados nas imagens a seguir.
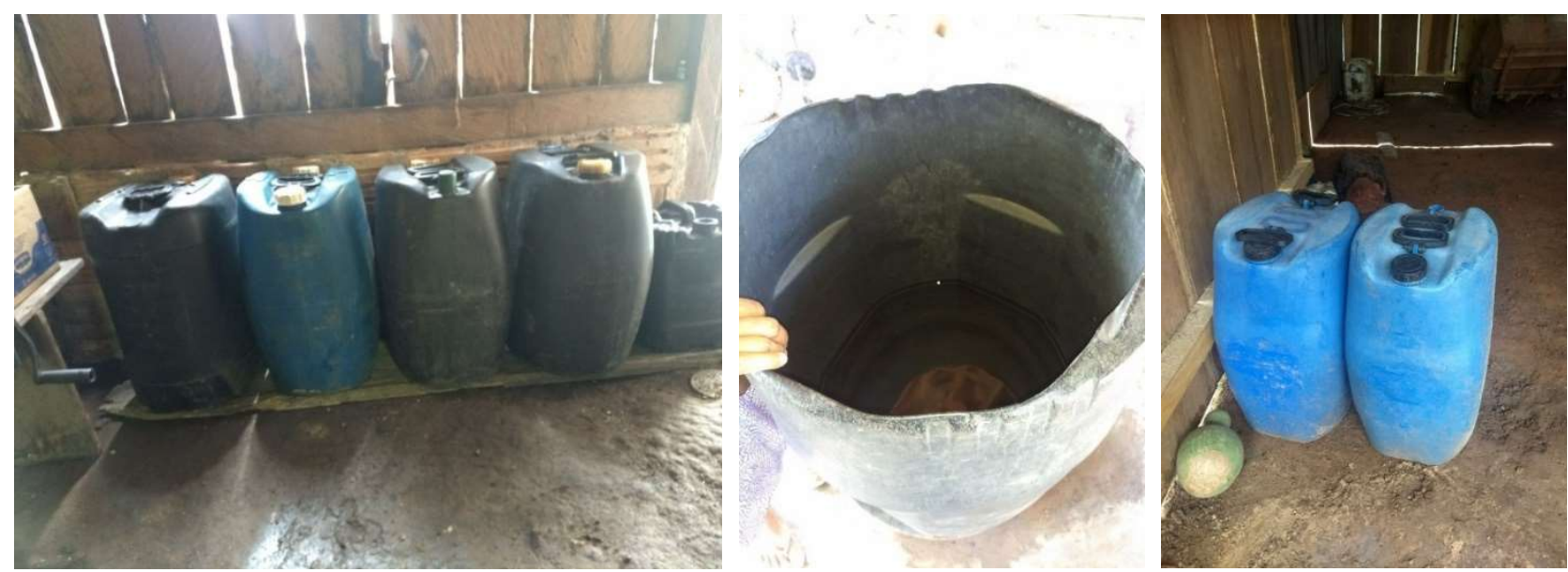

Imagem 1: Água coletada na fonte principal e armazenada para o consumo humano

De acordo com os dados da Funasa (2017), no Brasil, 72,2\% da população rural ainda acessa água apenas por meio de poços, cacimbas, açudes e barreiros, acesso esse muitas vezes precário e com grande potencial para provocar doenças de veiculação hídrica. As principais doenças são: amebíase, giardíase, 
gastroenterite, febre tifoide e paratifoide, hepatite infecciosa e cólera. A esquistossomose, ascaridíase, teníase, oxiuríase e ancilostomíase são verminoses transmitidas de forma indireta pela água. Já os vetores, como o mosquito Aedes aegypti, que se relacionam com a água, podem ocasionar a dengue, a febre amarela e a malária (MELO, 2014).

A falta de água potável e de tratamento adequado das águas tem como principal impacto a saúde das famílias, quando as pessoas não têm água de qualidade para consumo se desencadeia um processo em que "as pessoas são forçadas a ingerir água contaminada imprópria para consumo humano ficando expostas as doenças de veiculação hídrica e comprometendo a saúde de suas famílias" (CORDEIRO et al., 2010).

Quando questionadas sobre a qualidade da água, as respostas foram unânimes relatando ser de qualidade boa, porém com algumas queixas com relação à coloração e ao odor em determinadas épocas do ano.
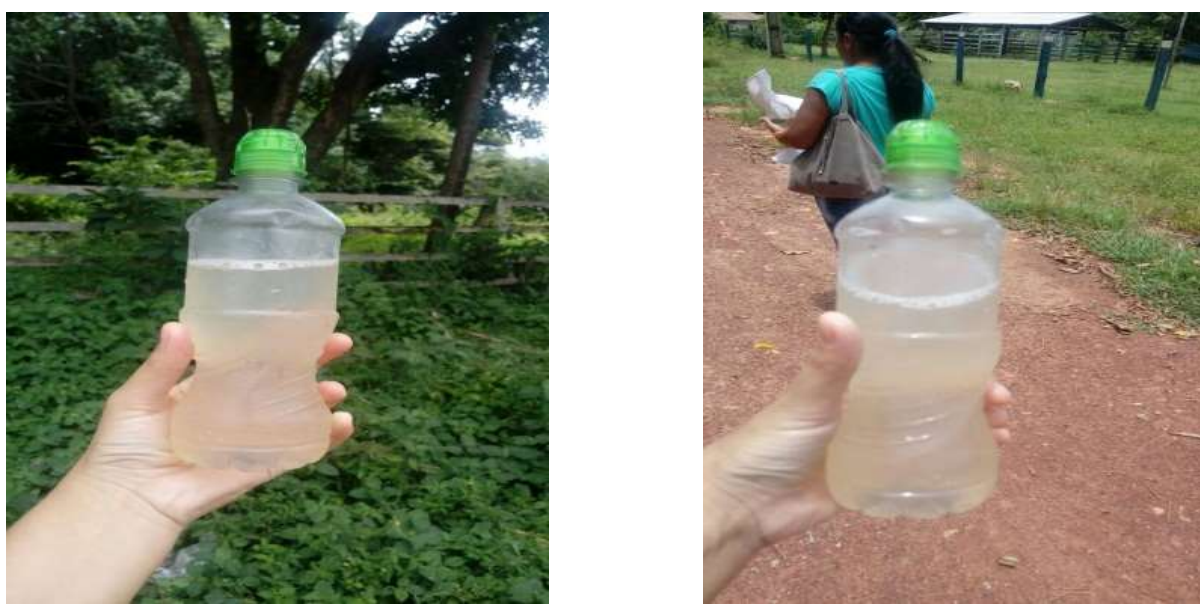

Imagem 2: Aspectos da água coletada da fonte .

A água deve estar disponível em quantidade suficiente para uso pessoal e doméstico; deve ser acessível, segura e de qualidade e não representar risco à saúde; dever ter cor, cheiro e sabor aceitáveis evitando que o indivíduo busque fontes alternativas não seguras (ONU, 2016; SILVA; HELLER, 2016).

Consequentemente a água designada ao consumo humano com relação aos seus "usos principais", como ingestão, higiene e o preparo de alimentos, deve respeitar algumas especificações para poder ser considerada segura, estar disponível continuamente e em quantidade suficiente para atender a todas as necessidades domésticas, ter custo acessível e não apresentar risco a saúde. Estas condições podem ser abreviadas em cinco palavras-chave: quantidade, qualidade, continuidade, cobertura e custo (OPAS, 2001).

A organização Pan-Americana da Saúde (OPAS) e o Programa das Nações Unidas para o desenvolvimento (PNUD) ressaltam nos trechos citados abaixo afirmações que, inclusive, aparecem em justificativas provenientes do senso comum com relação a importância da água (SILVA, 2012).

A água e a saúde das populações são duas coisas inseparáveis. A disponibilidade de água de qualidade é uma condição indispensável para a própria vida e mais que qualquer outro fator, a qualidade da água condiciona a qualidade de vida (OPAS, 2010).

[...] Quando as pessoas veem negado o seu acesso à água potável no lar ou quando não têm acesso à água enquanto recurso produtivo, as suas escolhas e liberdades são limitadas pela doença, pobreza e vulnerabilidade. A água dá vida a tudo, incluindo o desenvolvimento humano e a liberdade humana (PNUD, 2006). 
Quando questionadas sobre como era o abastecimento de água há 5 ou 10 anos atrás, as entrevistadas, que serão denominadas por nomes de flores para preservação de suas identidades, responderam que:

"Sempre foi coletada da mina, sempre foi vindo da mina, sempre foi coletado de lá" (Violeta, Assentamento Laranjeiras I).

"Então era do mesmo jeito, a gente precisava de água e vinha aqui buscar, aqui na mina perto da escola" (Margarida, Assentamento Laranjeiras I).

"Há cinco anos eu acho que não mudou muita coisa não, continua a mesma coisa, a gente vem buscar aqui na sede, a água, que a água que eu tenho em casa é a água salobra, (Rosa, Assentamento Laranjeiras I).

"Era bem ruim" (Orquídea, Assentamento Laranjeiras I).

"Buscava água todo dia para fazer tudo lá em casa” (Lírio).

Através das falas foi possível constatar que pouco se avançou no processo de obtenção de água, no entanto algumas famílias conseguiram adquirir água em seus lotes através da perfuração de poços. Conforme as falas e imagem a seguir:

"Hoje a gente tem poço, mas a antes a gente usava a mina aqui da sede" (Lotus, Assentamento Laranjeiras I).

"Eu encanei aí agora a água vai na minha casa, e tem mais cinco famílias que buscam água na minha casa de carrinho, eles vão buscar água lá para beber (...)” (Begônia, Assentamento Laranjeiras I).

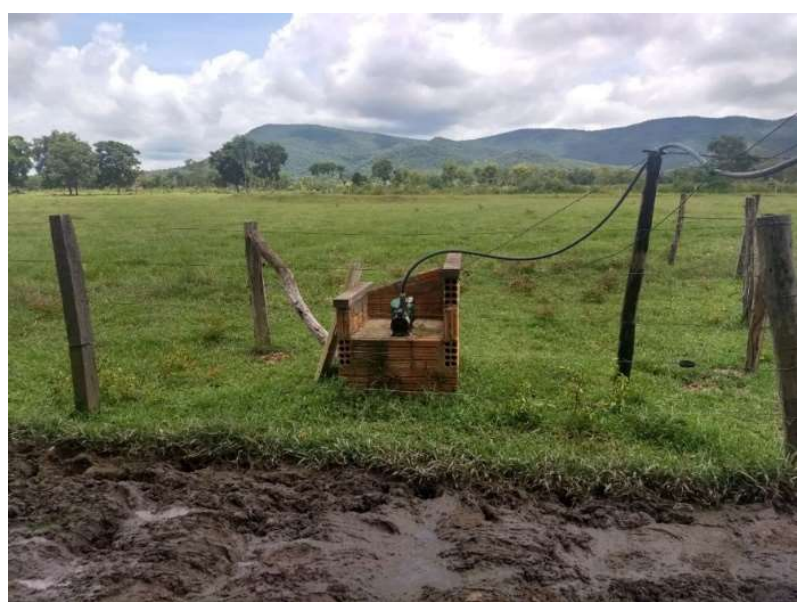

Imagem 3: Poço perfurado em residência.

Quando interrogadas sobre a forma de locomoção para a coleta de água tivemos as seguintes respostas:

"ai eu tenho que vim buscar principalmente na época da seca, ai eu venho de moto com os tambores pra ter a água boa em casa bebível" (Rosa, Assentamento Laranjeiras I).

"ai eu pegava e vinha buscar de balde, hoje busco de moto com os tambor" (Tulipa, Assentamento Laranjeiras I).

De acordo com a OMS, no que diz respeito à facilidade na obtenção da água, a população deve ter pelo menos o acesso básico à água para o consumo humano, sendo a fonte a uma distância máxima de $1 \mathrm{~km}$ do local de uso, ou cujo tempo de coleta dure entre 5 a 30 minutos, e que seja possível obter, no mínimo 20 litros de água por dia por membro da família (WHO, 2003). No levantamento publicado pela OMS e UNICEF 
(2017) não houve avanços significativos no que tange ao acesso à água, sendo que cerca de 263 milhões de pessoas se deslocam mais de 30 minutos para ter acesso a uma fonte de água segura.

Além de representar uma sobrecarga no trabalho, esta situação expõe a comunidade a problemas de saúde por doenças relacionadas ao consumo de água de má qualidade, e quando a distância para a fonte de água é superior a 30 minutos, coleta-se um volume menor do que o estimado para as necessidades domésticas, o que compromete a higiene e resultam no aparecimento de doenças (CORDEIRO et al., 2015).

A inacessibilidade à água potável em áreas rurais provoca o processo de êxodo rural, onde as famílias migram para outras localidades ou periferias urbanas com expectativa de terem acesso a esse direito em um outro contexto. No Assentamento Laranjeiras I também foi constatado que muitas famílias por vezes ansiaram pelo desejo de ir embora do assentamento devido a problemática da falta de água:

\footnotetext{
“Os vizinhos já pensaram em ir embora, por que como que vamos cozinhar, lavar..., eles desanimam de vez em quando querendo ir embora por causa da falta de água, vender o lote e ir embora..." (Hortência, Assentamento Laranjeiras I).
}

As mudanças no regime e na oferta de água provocam consequências diretas em seus meios de subsistência, requerendo estratégias de adaptação por parte da comunidade. Condições satisfatórias de abastecimento de água em quantidade e qualidade adequadas resultam em melhoria das condições de vida e em benefícios como controle e prevenção de doenças, prática de hábitos higiênicos, conforto e bem-estar, aumento da expectativa de vida e da produtividade econômica (RAZZOLINI; GÜNTHER, 2008). Por outro lado, a escassez de água afeta amplamente outros direitos humanos, inclusive os direitos à saúde, moradia adequada, educação e alimentação (ONU, 2016).

Foram observados também conflitos entre os moradores do assentamento relacionado ao uso da água, onde famílias disputam por minas e lançam mão de estratégias como a instalação de diversos encanamentos que levam a água às residências:

O que a gente vê muito é a falta de união, porque, por exemplo, tem a mina aqui da sede, em vez de todo mundo fazer uma caixa grande, mas não, cada um coloca um cano e faz um buraquinho, entendeu? Cada um quer fazer seu pocinho, ai vai diminuindo a água da mina (Magnólia, Assentamento Laranjeiras I).

Por que o povo aqui não tem humildade com as pessoas, tem uns que quer a agua mais pra eles, né, tem uns que dá a agua pro gado da mina né, então aí quando tá a agua pouca, quando a gente vai lá que passa água para a casa da gente eles vão e passa para a casa deles, aí é aquele sufoco na seca (Jasmim, Assentamento Laranjeiras I).

A redução da disponibilidade de água também irá intensificar ainda mais a disputa pela água por seus usuários, incluindo a agricultura, a manutenção de ecossistemas, assentamentos humanos, a indústria e a produção de energia. Isso afetará os recursos hídricos regionais, a segurança energética e alimentar, e potencialmente a segurança geopolítica, provocando migrações em várias escalas (UNESCO, 2016). Foi possível identificar que as famílias adotaram medidas de adaptação para superar a falta de água como a coleta e captação da água da chuva como mostra as imagens abaixo. 


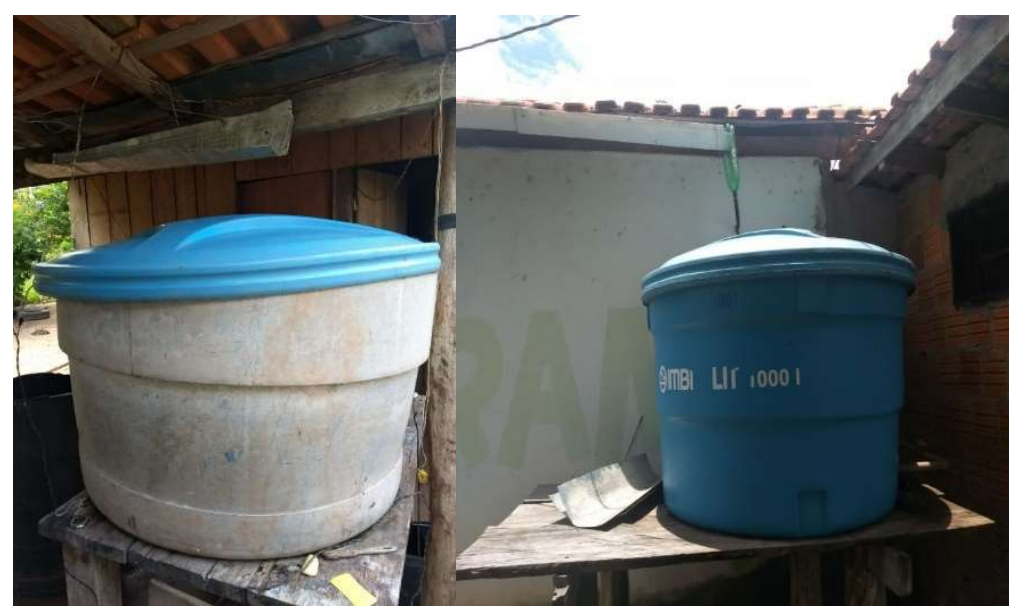

Esse tipo de tecnologia tem sido utilizado como tentativa de amenizar o problema da escassez de água, sendo inúmeras as vantagens de captação e aproveitamento da água da chuva, representando uma fonte alternativa de água com qualidade razoável para vários usos.

\section{CONCLUSÕES}

No que diz respeito à falta de água no assentamento, mais da metade das famílias entrevistadas necessitam recorrer diretamente de cursos de água sem nenhum tratamento ou de outras fontes alternativas como nascentes, poços e rios da região que podem estar contaminados e geralmente são inadequados para consumo humano. Este cenário contribui direta e indiretamente para o surgimento de doenças de transmissão hídrica.

Em muitos casos, a água pode conter uma grande quantidade de contaminantes físico-químicos e biológicos, o que pode gerar vários problemas de saúde, requerendo desta forma análise recorrentes sobre os parâmetros de água potável para consumo humano.

O estudo também revelou que todas as entrevistadas utilizam tambores e garrafas pet para o armazenamento da água, prática que merece atenção redobrada sobre as condições destes reservatórios alternativos, uma vez que podem ser fontes de contaminação para a saúde humana se não for armazenada corretamente.

Desta maneira se torna necessário a implementação de forma efetiva do manual de boas práticas no abastecimento de água proposto pelo ministério da saúde que traz subsídios para a minimização de riscos à saúde e a garantia de que a água consumida pela população atenda ao padrão e às normas estabelecidas na legislação vigente, com o propósito de avaliar os riscos que a água consumida representa para a saúde humana.

Outra medida que podem reverter este quadro trata-se da inclusão social dos grupos sociais minoritários, mediante a implantação integrada com outras políticas públicas setoriais, tais como: saúde, habitação, igualdade racial e meio ambiente.

Levando em consideração que a principal fonte de água da comunidade são as nascentes se torna necessário à preservação e conservação das mesmas, sendo que as estratégias de preservação das nascentes 
devem englobar pontos básicos como: controle da erosão do solo por meio de estruturas físicas e barreiras vegetais de contenção e a minimização de contaminação química e biológica.

A captação da água da chuva também deve ser fator de investigação com relação ao método utilizado e seu gerenciamento requer assessoria e capacitação técnica, de forma frequente. As soluções alternativas não necessariamente estão sob controle do poder público, ou seja, a solução para o abastecimento de água é construída pela própria população, em geral, a mais carente.

Um dos principais problemas identificados por meio das observações é a ausência de políticas públicas que garantem o acesso desta população a água e saneamento seguros, portanto ferem os direitos ao atendimento de necessidades básicas como a saúde, moradia adequada, educação e alimentação.

Em 2015, foram estabelecidos os 17 Objetivos do Desenvolvimento Sustentável-ODS com 169 metas. O Objetivo 6, dedica-se especialmente ao acesso à água segura. A meta 6.1 apresenta de forma explicita o acesso universal e equitativo, além disso, o documento pressupõe que até o ano de 2030 todos tenham acesso ao saneamento e higiene adequados e equitativos, acesso à água de qualidade de forma efetiva, gestão integrada dos recursos hídricos, proteção ao ecossistema hídrico, redução pela metade do uso da água sem tratamento e redução substancialmente do número de pessoas que sofrem com a escassez de água, no entanto a comparação entre o compromisso dos ODS e a situação atual da população da comunidade rural Laranjeiras I, demanda a necessidade de planejamento e investimentos, considerando diversas formas de gestão, incluindo a possibilidade de gestão comunitária.

Outro ponto que deve ser levado em consideração é a sobrecarga de trabalho dos moradores com relação à busca de água. Dessa forma, pode-se verificar que o acesso à água, ao mesmo tempo, atua em uma importante dimensão da vulnerabilidade da população rural.

Ademais, partes das entrevistadas relataram que um dos problemas nas relações sociais existentes no assentamento e que prejudica toda a população frente ao problema de escassez hídrica é a falta de união, falta de organização coletiva da comunidade para lutar e viabilizar meios para acesso à água por toda a comunidade rural. Outra questão levantada é a falta de tecnologias e saberes ambientalmente adequados.

Nenhuma iniciativa isolada é capaz de atender plenamente à demanda de água para consumo doméstico e produtivo das famílias rurais, sendo que a diversidade de técnicas adotadas para a regularização da oferta de água no assentamento decorre de uma necessidade proveniente da singularidade das situações.

Embora, as respostas que garantem a mitigação dos problemas socioambientais do Assentamento Laranjeiras I tenham sido iniciadas desde o final do ano de 2010, muito ainda precisa ser feito em relação a vários aspectos deste assentamento. Ações da população residente também têm sido identificadas, porém com enfoque na individualidade das famílias, como quando puxam canos para coleta familiar.

A dificuldade encontrada pela comunidade rural do Assentamento Laranjeiras I com relação à escassez hídrica, apesar deste assentamento estar em uma região de abundância de água, é a ausência de políticas públicas para acesso e permanência das populações em áreas rurais em projetos de assentamento, por exemplo, têm sido cada vez mais fragilizados em função das políticas públicas que asseguram o desenvolvimento e avanço do agro e hidro negócio. 
Mobilizações com relação à privatização da terra e da água também têm sido feitos em função das práticas governamentais no que tange a privatização desse bem público ao capital internacional, como nos aponta o Fama (Fórum alternativo da água) que é composto por diversos movimentos, onde os projetos são pautados pelos interesses do povo e tem como objetivo debater temas como o controle social das fontes de água, o acesso democrático a água, a luta contra as privatizações dos mananciais e barragens, a defesa dos povos atingidos, os serviços públicos de água e saneamento e as políticas públicas necessárias para o controle social do uso da água e preservação ambiental.

Por fim, esta realidade da comunidade estudada evidencia a necessidade de transformações estruturais e ações que visam ampliar o acesso aos sistemas de abastecimento de água. Atender aos excluídos de o acesso demanda reconhecer a situação de alta vulnerabilidade na qual essa parcela da população está inserida e considerar as múltiplas dimensões e a diversidade de desafios para a efetividade de ações setoriais, como são as intervenções em abastecimento de água para consumo humano.

Ressalta-se que a vulnerabilidade da população rural tem uma nítida relação com a exclusão do acesso às políticas públicas, o que não implica desconsiderar a riqueza cultural, ambiental e de alternativas criativamente produzidas nessas regiões.

\section{REFERÊNCIAS}

BERNARD, H. R.. Research methods in cultural anthropology. United States of America: Sage Publications, 1988.

BRASIL. Instituto Nacional de Colonização e Reforma Agrária - INCRA. Assentamentos. 2014.

CASTRILLON, S. I.; PUH, J. I.; MORAIS, F. F.; LOPES, A. A. E. M.. Escassez hídrica e restauração ecológica no pantanal: recuperação das nascentes e fragmentos de mata ciliar do córrego no Assentamento Laranjeira I e mobilização para conservação dos recursos hídricos no Pantanal matogrossense. Cuiabá: Carlini \& Caniato, 2017.

CORDEIRO, R. L. M.; SILVEIRA, S. M. B.; MORALES, P.; ALMEIDA, $V$.. Mulheres e água : a experiência da rede de mulheres rurais da América Latina e do Caribe. Revista ANTHROPOLÓGICAS, Recife, v. 23, n. 1, 2012.

CORDEIRO, R. L. M.; SILVEIRA, S. M. B.; MORALES, P.; CLEMENTE, F. S. mulheres rurais e as lutas pela água na América Latina. Temporalis, Brasília, v.15, n.30, p.495-514, 2015.

FUNASA. Panorama do Saneamento Rural no Brasil. Brasília, 2017.

GIL, A. C.. Como elaborar projetos de pesquisa. 4 ed. São Paulo: Atlas, 2009.

GODOY, A. S.. Pesquisa qualitativa: Tipos Fundamentais. RAE: Revista de Administração de Empresas, 1995.

GREY, D.; GARRICK, D.; BLACKMORE, D.; KELMAN, J.; MULLER, M.; SADOFF, C. Water security in one blue planet: twenty-first century policy challenges for science. The Royal
Society Publishing, v. 371, n. 20120406, p.1-10, 2013. DOI: http://doi.org/10.1098/rsta.2012.0406

MELO, M. C. H.; CRUZ, G. C.. Roda de Conversa: uma proposta metodológica para a construção de um espaço de diálogo no Ensino Médio. Imagens da Educação, Maringá, v.4, n.2, p.31-39, 2014.

MELO, A. V.. Análise dos recursos hídricos, do saneamento básico e das doenças de veiculação hídrica nos bairros Paracurí e Águas Negras em Belém /PA. Dissertação (Mestrado em Geografia) - Pontifícia Universidade Católica de São Paulo, São Paulo, 2014.

ONU. Transformando Nosso Mundo: A Agenda 2030 para o Desenvolvimento Sustentável. Tradução Centro de Informação das Nações Unidas para o Brasil (UNIC Rio), Brasília: ONU, 2015.

ONU. Assembleia Geral das Nações Unidas. Relatório do Relator Especial sobre o direito humano à água potável segura e ao esgotamento sanitário. 2016.

OPAS; OMS. Água e saúde. Brasil, 2001.

PNUD. Relatório do Desenvolvimento Humano 2006. A água para lá da escassez: poder, pobreza e a crise mundial da água. Nova lorque: PNUD, 2006.

RAZZOLINI, M. T. P.; GÜNTHER, W. M. R.. Health Impacts Due to Deficient Water Access. Saúde e Sociedade, São Paulo, v.17, n.1, p.21-32, 2008. DOI: http://dx.doi.org/10.1590/S0104-12902008000100003

SILVA, C. V.. Efeitos da implantação de cisternas para armazenamento de água de chuva na saúde infantil: estudo 
quase experimental na área rural de dois municípios do semiárido mineiro. Tese (Doutorado em Saneamento, Meio Ambiente e Recursos Hídricos) - Universidade Federal de Minas Gerais, Belo Horizonte, 2012.

SILVA, T. P.; BINZSTOK, J. Espaços de resistência camponesa na fronteira Brasil-Bolívia: os assentamentos rurais em Cáceres-MT. Observatório Geográfico da América Latina, 2013.

SILVA, P. N.; HELLER, L. O direito humano à água e ao esgotamento sanitário como instrumento para promoção da saúde de populações vulneráveis. Ciência \& Saúde Coletiva, v.21, n.6, p.1861-1869, 2016. DOI:

http://dx.doi.org/10.1590/1413-81232015216.03422016

UNESCO. Relatório Mundial das Nações Unidas sobre Desenvolvimento dos Recursos Hídricos. Colombella:
WWAP, 2015

UNESCO; WWAP. Relatório Mundial das Nações Unidas sobre Desenvolvimento dos Recursos Hídricos 2016: Água e Emprego. Colombella: WWAP, 2016.

WHO; UNICEF. Progress on Drinking Water and Sanitation: Special Focus on Sanitation. Geneva: World Health Organization. New York: UNICEF, 2008.

WHO; UNICEF. Joint Monitoring Programme for Water Suplly, Sanitation and Hygiene. Geneva: World Health Organization. New York: UNICEF, 2016.

WHO; UNICEF. Progress on Drinking Water, Sanitation and Hygiene. Geneva: World Health Organization. New York: UNICEF, 2017.

A CBPC - Companhia Brasileira de Produção Científica (CNPJ: 11.221.422/0001-03) detém os direitos materiais desta publicação. Os direitos referem-se à publicação do trabalho em qualquer parte do mundo, incluindo os direitos às renovações, expansões e disseminações da contribuição, bem como outros direitos subsidiários. Todos os trabalhos publicados eletronicamente poderão posteriormente ser publicados em coletâneas impressas sob coordenação da Sustenere Publishing, da Companhia Brasileira de Produção Científica e seus parceiros autorizados. Os (as) autores (as) preservam os direitos autorais, mas não têm permissão para a publicação da contribuição em outro meio, impresso ou digital, em português ou em tradução. 